\title{
Mixed Neoplasm
}

National Cancer Institute

\section{Source}

National Cancer Institute. Mixed Neoplasm. NCI Thesaurus. Code C6930.

A neoplasm composed of at least two distinct cellular populations. 